\title{
The expression of clock genes cry1 and cry2 in human colorectal cancer and tumor adjacent tissues correlates differently dependent on tumor location
}

\author{
K. HASAKOVA ${ }^{1}$, M. VICIAN ${ }^{2}$, R. REIS ${ }^{3}$, M. ZEMAN ${ }^{1}$, I. HERICHOVA ${ }^{1}$ \\ ${ }^{1}$ Department of Animal Physiology and Ethology, Faculty of Natural Sciences, Comenius University Bratislava, Bratislava, Slovak Republic; \\ ${ }^{2}$ Fourth Surgery Department, University Hospital, Comenius University Bratislava, Bratislava, Slovak Republic; ${ }^{3}$ First Surgery Department, \\ University Hospital, Comenius University Bratislava, Bratislava, Slovak Republic
}

*Correspondence: herichova1@uniba.sk

Received January 22, 2018 / Accepted April 24, 2018

\begin{abstract}
Colorectal cancer (CRC) exhibits differences in its features depending on the location of the tumor. The role of the circadian system in carcinogenesis is accepted, and many studies report different clock gene expression in tumors compared to healthy tissue. However, little attention is given to the changes in clock genes in tumors arising from various locations across the colon and rectum. The aim of our study was to investigate the expression of the clock genes cry 1 and cry 2 in human CRC tissue and tissue adjacent to colorectal tumors in a cohort of 64 patients by real time PCR. Expression of cry 1 in the entire patient cohort was higher in tumors compared to adjacent tissues in the right-sided colon but not in the left-sided colorectum. Difference in cryl expression between tumor and adjacent tissue in the right-sided colon was preserved in women and a trend was observed in men. Higher expression of cry 1 in the right-sided colon tumor tissue was associated with worse survival in women and the expression of cry 1 in the left-sided colorectum was significantly higher in the adjacent tissue compared to tumor in men but not in women. Expression of cry 2 was lower in the tumor than in adjacent tissue in both the right and left-sided colorectum. This trend was generally preserved, but the difference reached significance level only in the male left-sided colon, and cry 2 expression in the tumor tissue significantly correlated with location of the tumor in men with grade 2 cancer. Finally, we detected significant correlation between tumor location and cry 1 expression in the adjacent tissue and the combined results establish that tumor influence on adjacent tissue is dependent on tumor location. Changed clock gene expression should therefore be considered in specific CRC patient sub-groups.
\end{abstract}

Key words: circadian, cryptochrome, grade, gender, left-sided colorectum, right-sided colon

The circadian rhythm is an endogenous timekeeping mechanism comprising autonomous peripheral oscillators that are coordinated by a master oscillator located in the supra-chiasmatic nucleus (SCN) of the hypothalamus. The SCN generates 24 hour circadian rhythms in physiology, metabolism, and behavior. The molecular principle of this rhythm generation is based on the oscillations of clock genes that form a transcription-translation feedback loop. The positive arm of the feedback loop is formed by BMAL1 and CLOCK which belong to the family of basic helix-loop-helix transcription factors that heterodimerize, and through binding to the E-box element in the promoter region they activate the transcription of the negative elements of the loop period (per1-3) and cryptochrome (cry1 and 2) genes. CRY and PER proteins continuously accumulate in the cytoplasm and after translocation to the nucleus, they repress their own transcription [1]. Degradation of CRY and PER proteins is required for the end of repression and start of the new cycle. The process described above takes approximately 24 hours and determines the circadian period [2].

The link between the circadian system and colorectal cancer (CRC) is supported by experiments employing per 2 deficient mice. $\gamma$-irradiation accelerated tumor growth and decreased levels of apoptosis in thymocytes in per $2^{-/-}$mice [3]. The circadian rhythm in expression of per1, per2, $d b p$, and reverb alpha is reduced, and the rhythm of bmall is completely abolished in mice with experimentally induced CRC compared to normal colonic tissue [4]. In contrast, cry $1^{-/-}$cry $2^{-/-}$double knock-out or clock $^{-/-}$mice are not more sensitive to $\gamma$-irradiation, and these mutants are indistinguishable from the wild-type mice $[5,6]$. However, when a 
mutation of cry genes was combined with mutation of $p 53$, these mice were resistant against the early onset of cancer and had their lifespan extended approximately by $50 \%$ compared with mice solely with p53 mutation [7]. Difference was also found in the rate of apoptosis. Ultraviolet (UV) and oxaliplatin induced apoptosis was enhanced in Ras-transformed cells isolated from cry1/cry2/p53 homozygous mutants compared to $p 53^{-/-}$Ras-transformed cells [8].

The circadian system is also involved in DNA repair; in particular, the circadian system influences excision repair which in humans is performed by six core repair factors. One of the repair factors is xeroderma pigmentosum (XPA) which is directly controlled by the circadian feedback loop and exerts a daily oscillation. In the liver of $c r y 1 / 2^{-/-}$double mutant mice, XPA is constitutively over-expressed and its daily rhythm is abolished. This change in XPA activity influences excision repair activity only marginally $[9,10]$.

In our study, we focused on the location of colorectal tumors. The colon exerts molecular, anatomical and bacterial changes in the proximal and distal tract and rectum, so it is not surprising that carcinomas arising from different parts of the colon show this diversity [11]. An increased immune activity in the caecum of the proximal colon in comparison to the rectum was observed in healthy probands [12]. Differences in the colon's immune system can arise from concentrations of the microbiota in the gut, which increases from proximal to distal colorectum [13]. Proximal or right-sided tumors occur more often in older patients and females and have a higher TNM stage at presentation than distal or left-sided carcinomas. In contrast to right-sided CRC, the incidence of left-sided tumors is decreasing. Epidemiological data indicates that patients with distal tumors have better overall survival. Genetic and epigenetic causes of CRC exert differences dependent on tumor location. Microsatellite instability and methylation of mismatch repair genes are typical for proximal tumors, while chromosomal instability with inactivation/deletion of tumor suppressor genes is more characteristic for distal tumors [14].

Herein, we analyze the expression pattern of $c r y 1$ and $c r y 2$ genes in CRC and tissue adjacent to tumors and focus on tumor location.

\section{Patients and methods}

The study involved 64 patients of both genders with previously diagnosed colorectal cancer (CRC - 38 men, 26 women) with average age $69 \pm 12$ years. All patients were exposed to standard hospital practice with lights on from 6:00 a.m. to 9:00 p.m. (The First and the Fourth Surgery Departments, University Hospital, Comenius University, Bratislava). The protocol was explained and informed consent was obtained from all participants. The experimental protocol was approved by the Ethics Committee. Histopathological examinations were performed by a hospital patholo- gist and tissue samples were collected from the tumor and the proximal $(\geq 10 \mathrm{~cm}$ above the tumor) and distal $(\geq 2 \mathrm{~cm}$ below the tumor) parts of the resected colon. The surgery was conducted between 10:00 a.m. and 1:00 p.m. Tissue samples were placed in liquid nitrogen and stored at $-80{ }^{\circ} \mathrm{C}$ until further processing. A detailed description of the patient cohort in this study is in Table 1.

Gene expression analysis. Total RNA was isolated from the tissue samples using RNAzol reagent (MRC, USA) according to the manufacturer's instructions. cDNA was synthesized with the ImProm-II Reverse Transcription System (Promega, USA)II according to manufacturer's instructions. Relative quantification of cry 1 and cry 2 was performed with the QuantiTect SYBR Green PCR Kit (Qiagen, Germany) and the StepOne Real-Time PCR Systems (Applied Biosystems, USA). Primers for the detection of cry1, cry2, and U6 were: cry1 (NM_004075.4) sense 5'-CCGTCTGTTTGTGATTCGTG-3', antisense 5'-AAGTTAGAGGCGGTTGTCCA-3'; cry2 (NM_001127457.2) sense 5'-GGAGGCTGGTGTGGAAGTAG-3', antisense 5 '-CGTAGGTCTCGTCGTGGTTC-3'; and U6 (NR_004394.1) sense 5'-GCTTCGGCAGCACATATACTAA-3', antisense 5'-AAAATATGGAACGCTTCACGA-3'. Real-time PCR conditions were: activation of hot-start polymerase at $95^{\circ} \mathrm{C}$ for $15 \mathrm{~min}$ followed by 50 cycles at $94^{\circ} \mathrm{C}$ for $15 \mathrm{~s}, 49^{\circ} \mathrm{C}$ for $30 \mathrm{~s}\left(52^{\circ} \mathrm{C}\right.$ for U6), and $72^{\circ} \mathrm{C}$ for 30 s. The specificity of PCR products was validated by melting curve analysis and U6 expression was used for normalization of clock gene expression.

To evaluate gene expression in tumor and adjacent tissue (Figure 1) and survival (Figure 2), sub-sites were categorized in the right-sided colon cancer (C18.0-C18.4) and left-sided colorectal cancer (C18.5-C20).

To perform regression analysis (Figure 3), the tumor locations $(\mathrm{C} 18, \mathrm{C} 19, \mathrm{C} 20)$ were transformed into numerical

Table 1. Clinical and pathological characteristics of patients.

\begin{tabular}{ll}
\hline Number of patients & $\mathbf{6 4}$ \\
\hline Men & 38 \\
Women & 26 \\
Tumor location & \\
C18 & 36 \\
C19 & 10 \\
C20 & 18 \\
Clinical stage & \\
I-II & 32 \\
III-IV & 32 \\
Grade & \\
1 & 12 \\
2 & 49 \\
3 & 3 \\
\hline
\end{tabular}

$\mathrm{C} 18=$ tumors located in colon, $\mathrm{C} 19=$ tumors located in rectosigmoid colon, $\mathrm{C} 20$ = tumors located in rectum 
data. Transformation was done by using an average distance of each section (colon, recto-sigmoid junction and rectum) to anus obtained from computed tomography colonography [15]. This approach has been accepted previously [16].

Statistical analysis. Paired t-test compared expression in the tumor and adjacent tissues in the right and leftsided colorectum. Survival curves were compared using the Gehan-Wilcoxon test and linear regression analysis determined the correlation between $c r y 1$ and cry 2 gene expression and tumor location.

\section{Results}

The expression of cry 1 was significantly up-regulated in tumor tissue compared to adjacent tissue in right-sided colon tumors ( $\mathrm{p}<0.01$, paired t-test). This was not observed in leftsided colorectal tumors. Expression of cry 2 was significantly lower in tumor tissue compared to adjacent tissue in both right and left-sided colorectal tumors, and more robust down-regulation was observed in the left-sided colorectum $(\mathrm{p}<0.001$, paired t-test, Figure 1A).
A

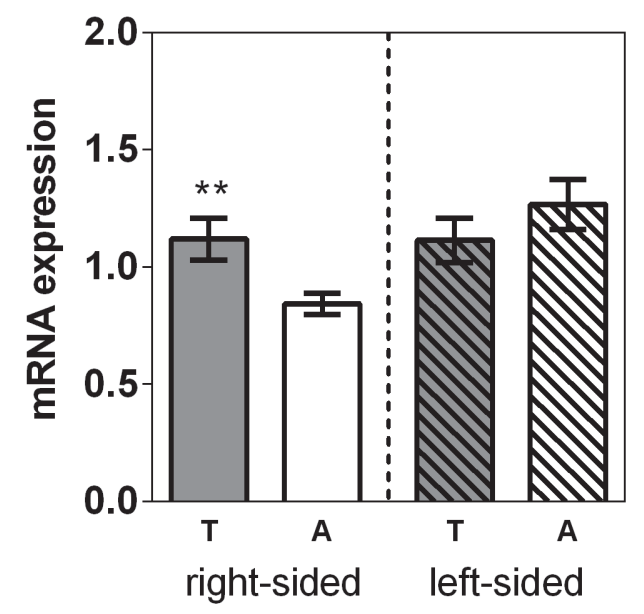

B

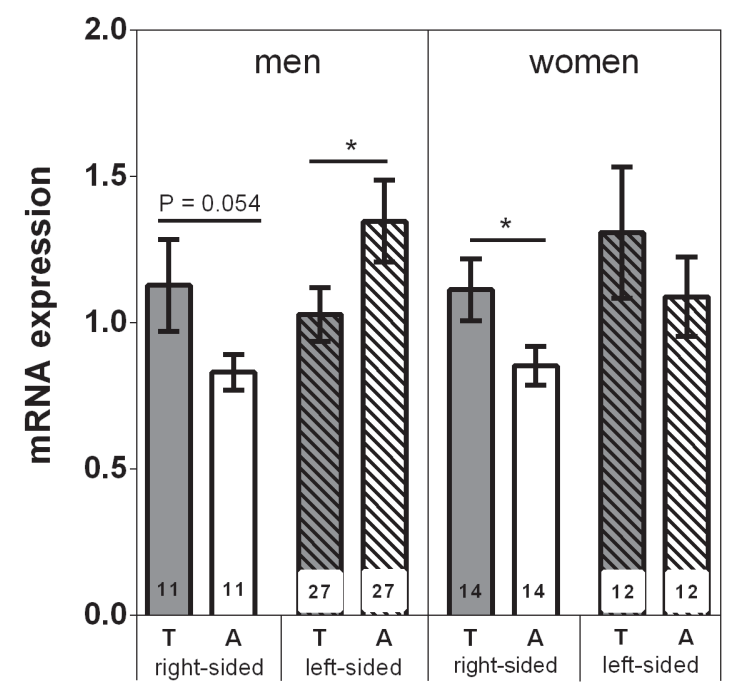

\section{cry1}

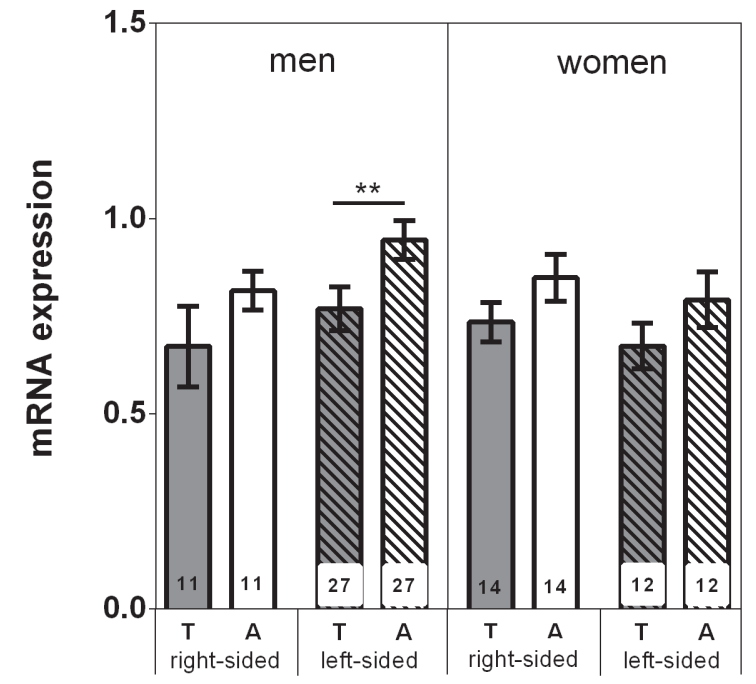

Figure 1. Expression of cry 1 and cry 2 in tumor and adjacent tissue. A) in the whole cohort of patients divided according to tumor location into rightsided tumors (C18.0-C18.4, $\mathrm{n}=25)$ and left-sided tumors $(\mathrm{C18.5}-\mathrm{C20}, \mathrm{n}=39)$. B) Sex-dependent expression of cry1 and cry2 in tumor and adjacent tissue in right-sided tumors and left-sided tumors. Numbers in columns indicate sub-group size. $\mathrm{T}$ - tumor tissue, $\mathrm{A}$ - adjacent tissue (averaged expression in the proximal and distal tissue resected during surgery); values are presented as means $\pm \mathrm{SEM} ;{ }^{*} \mathrm{p}<0.05 ;{ }^{* *} \mathrm{p}<0.01 ; \mathrm{paired} \mathrm{t}-\mathrm{test}$. 
After dividing the cohort according to gender, we detected significantly lower levels of cryl expression in tumor tissue compared to adjacent tissue in left-sided male tumors, but the opposite trend was observed in right-sided tumors $(\mathrm{p}=0.054$, paired $\mathrm{t}$-test). In women, expression of $c r y 1$ was up-regulated in tumor tissue compared to adjacent tissue in the right-sided colon $(\mathrm{p}<0.05$, paired $\mathrm{t}$-test) but this was not observed in the left-sided colorectum (Figure 1B).

Expression of cry2 was significantly lower in tumors located in the left-sided colorectum compared to adjacent tissue in men $(\mathrm{p}<0.01$, paired $\mathrm{t}$-test). Tumors located in the right-sided colon of men and women and left-sided colorectum of women showed the same pattern, but the difference did not reach significance (Figure 1B).

Higher expression of cryl in the right-sided colon tumor tissue was significantly associated with worse survival in women ( $\mathrm{p}=0.045$, Gehan-Wilcoxon test; Figure $2 \mathrm{~A})$. This association was not observed in the female cohort with tumors in left-sided colorectum (Figure 2B). In contrast, male patients did not exhibit correlation between survival and cry expression in right-sided or left-sided tumors (data not shown).

The cluster of male patients with grade 2 tumor (G2, moderately differentiated) exhibited significant correlation between cry 2 expression in tumor tissue and location $\left(\mathrm{p}=0.045 ; \mathrm{y}=-56.79^{\star} \mathrm{x}+99.72 ; \mathrm{R}=0.376 ; \mathrm{n}=29\right.$; Figure $\left.3 \mathrm{~A}\right)$. This was also present in adjacent tissue $\left(\mathrm{p}=0.009 ; \mathrm{y}=-90.58^{\star} \mathrm{x}\right.$ $+138.7 ; \mathrm{R}=0.474 ; \mathrm{n}=29$; Figure $3 \mathrm{~B}$ ). These correlations were not observed in the women's cohort (Figure 3). There was significant correlation between cryl expression in adjacent tissue and tumor location in men $\left(\mathrm{p}=0.003 ; \mathrm{y}=-36.50^{*} \mathrm{x}\right.$ $+100.9 ; \mathrm{R}=0.532 ; \mathrm{n}=29)$ and also in women $(\mathrm{p}=0.016$; $y=-56.66^{*} x+125.1, R=0.530 ; n=20$; Figure $3 B$ ). This correlation was not observed in the tumor tissue (Figure $3 \mathrm{~A}$ ).

\section{Discussion}

Our study revealed significant changes in cry 1 expression dependent on gender and tumor location. Expression of cry 1 was higher in tumors compared to adjacent tissue in the rightsided colon but not in the left-sided colorectum in the entire patient cohort. Difference in cryl expression between tumor and adjacent tissue in the right-sided colon was preserved in women, and a trend was observed in men. Higher expression of cry1 in the right-sided colon tumor tissue was associated with worse survival in women. Expression of $c r y 1$ in the left-sided colorectum was significantly higher in the adjacent tissue compared to tumor in men but not in women. We also detected significant correlation between tumor location and cry 1 expression in the adjacent tissue in both sub-groups of patients. These results establish that the tumor influence on adjacent tissue depends on tumor location.

Recent knowledge of CRC induced changes in cry1 expression is inconclusive [17-19]. It is possible that changes in cry 1 expression may be linked to certain clinical and pathological features because reduced levels of cry 1 expression were observed in females, older patients (62-74 years) and in tumors located in the transverse colon [18]. Another study reports the highest expression of cryl in tumors located in the distal colon compared to other colon parts [17]. This supports our results, since we detected a trend of correlation of $c r y 1$ expression in tumor tissue with tumor location in female patients; with the lowest expression in the proximal colon and the highest in the rectum. The link between cry expression and tumor location in individual groups of patients of the cohort may be related to the differences between the morphological and physiological states of right-sided colon and left-sided colorectal cancer tissue [14].
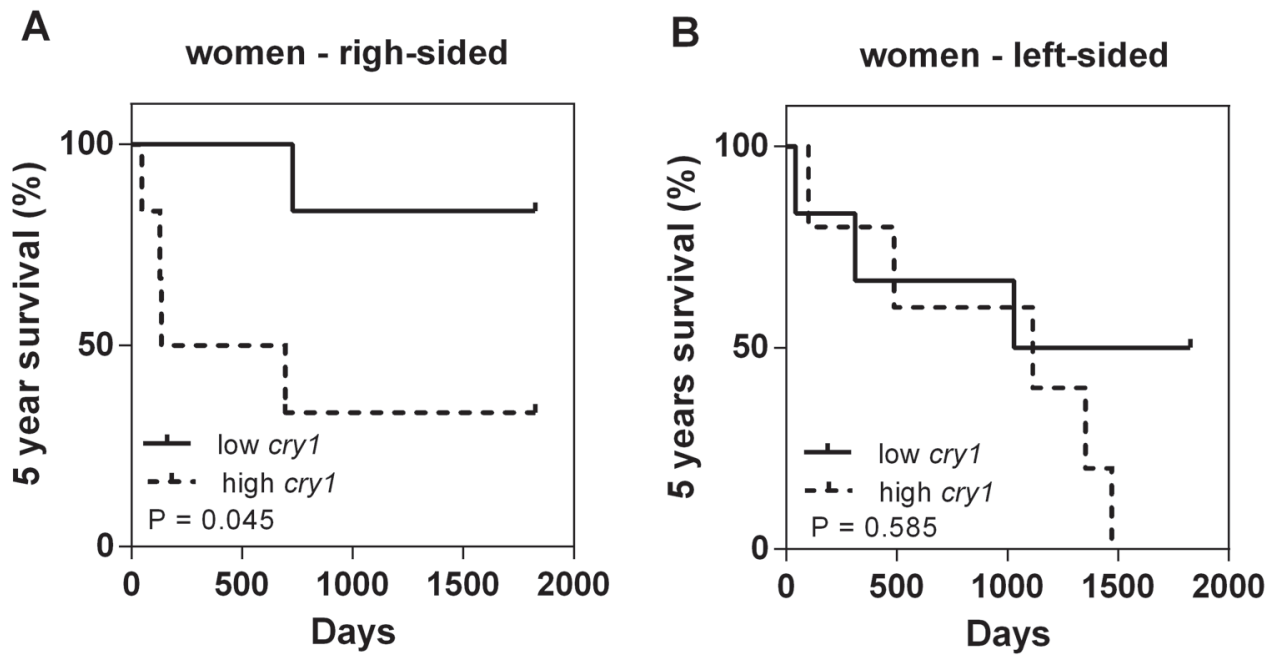

Figure 2. Five-year survival curves for women patients with tumors located in the (A) right-side of colon ( $\mathrm{n}=12)$ and (B) left-side of colorectum ( $\mathrm{n}=11$ ) sorted according to median of cryl expression. Solid line indicates low cry 1 expression ( $\leq$ median of expression in the cohort,) and dotted line indicates high cry1 expression (> median of expression in the cohort). $\mathrm{p}=$ level of significance (Gehan-Wilcoxon test). 


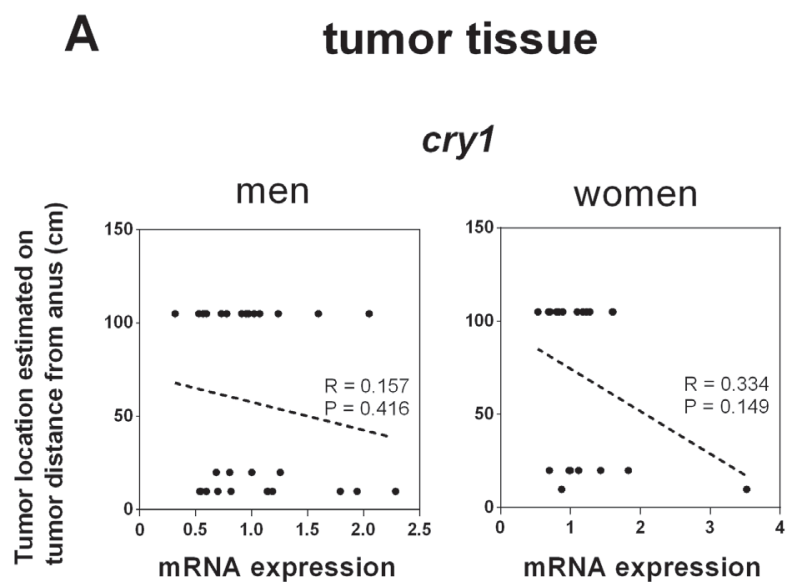

B

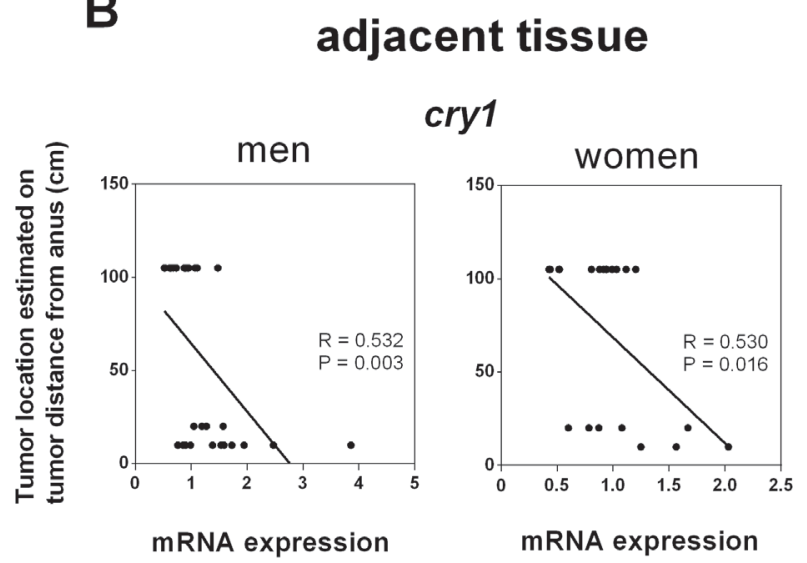

\section{tumor tissue}

cry2
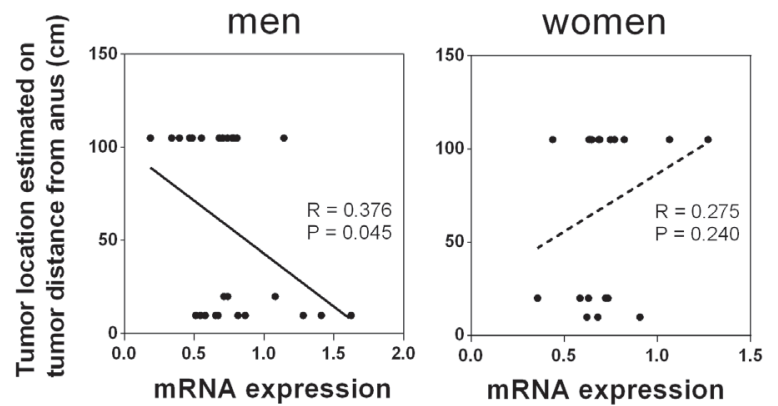

\section{adjacent tissue}

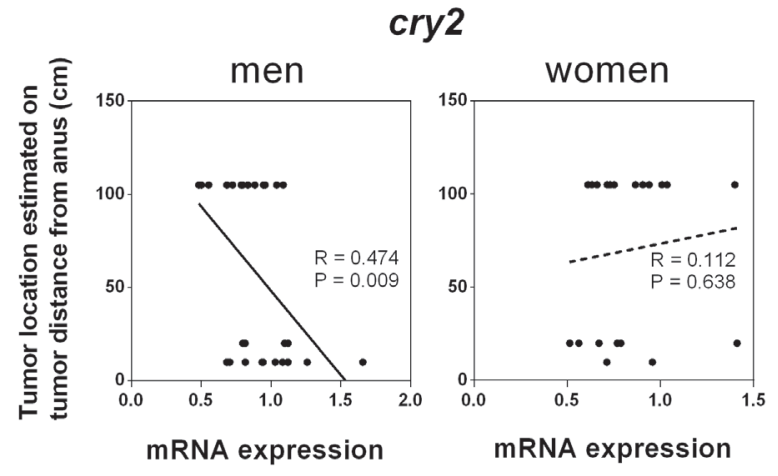

Figure 3. Correlation between tumor location and cry1 and cry2 expression in tumor (A) and tumor adjacent tissue (B) in patients with grade 2 (men, $\mathrm{n}=29$; women, $\mathrm{n}=20$ ). $\mathrm{mRNA}$ is given in relative units.

Expression of cry2 was lower in the tumor than in adjacent tissue in both the right and left-sided colon. This trend was generally preserved in sub-groups of patients, but the difference reached level of significance only in left-sided colorectum in men. There is a substantial data supporting the assumption that expression of cry 2 in colorectal tumor tissue differs in comparison to adjacent healthy mucosa [17, 18]. Expression of cry 2 was down-regulated in colorectal tissue, similar to other genes involved in the circadian feedback loop (i.e., per 1 and per2) [17, 18]. This agrees with our results, and also with the significant positive correlation between cry 2 expression in tumor tissue and tumor location observed in male patients with grade 2 , as in our original observation.

It is not clear if the above-mentioned gender-dependent differences are directly related to observed epidemiological changes in CRC incidence. It is accepted that proximal tumors (right-sided tumors) occur more often in females and older patients. Chemotherapy is more efficient in male patients with tumors in the proximal colon than in distal tumors, and this is not observed in women [20]. Patients with left-sided tumors benefit from anti-epidermal growth factor receptor (anti-EGFR) therapy more than patients with right-sided tumors [21]. We assume that improved knowledge of the gender, age and location-dependent spectrum of gene expression contributes to explanation of the epidemiological observation stated above.

In addition to clock gene expression, the different status of specific gene mRNA expression involved in the carcinogenesis of CRC was observed in proximal, distal and rectal cancer. Rectal cancer had higher levels of ERCC1 (DNA excision repair protein) and VEGFR (receptor for vascular endothelial growth factor) compared to proximal and distal tumors; and higher expression of thymidylate synthase (TS) compared to distal colon cancers. These findings support the above-mentioned observation that efficacy of antitumor treatment such as anti-angiogenic and flouropyrimidine agents may be related to tumor location [22]. 
Surprisingly, we also observed changes in clock gene expression in tissues adjacent to the tumors and considered healthy. There is no recent data on daily rhythms in clock gene expression in distinct parts of the human colon. Expression of cry 1 and $c r y 2$ genes in murine proximal, middle and distal colon exhibits daily rhythm. In all examined mice gastrointestinal tract tissues, the acrophase of cryl expression was observed at the end of the dark part of the light/dark cycle, while cry 2 expression peaked at the beginning of the dark part of the cycle [23]. Rhythmic clock gene expression in the GIT is regulated by both central and peripheral oscillators [24]. Changes in cry expression along the colon are partly explained by previously reported differences between the phase of clock gene expression in the upper (duodenum) and lower (distal colon) parts of the gastro-intestinal tract [25].

Tumorigenesis attenuates the daily rhythmic pattern of clock genes in the liver [26] and colon [4]. Therefore, it is possible that changes in daily rhythm of cry expression in tumor tissue can influence correlation between cry expression and tumor location in CRC tumor tissue.

The functional relationship between changed cry expression and cancer promotion is not completely elucidated, but there is substantial epidemiological evidence. Expression of cry1 significantly positively correlated with lymph node metastasis and the TNM stage of patients [19]. Similarly, patients with higher cry1 and cry2 expression had poorer survival rates [18] which accords with the above-mentioned observation.

At the molecular level, tumor promoting properties of cry genes have been demonstrated under several experimental conditions. Up-regulation of cry 1 expression promoted cancer cell proliferation and migration, while down-regulation induced inhibition of cancer cell migration [19]. The association of exogenous expression of both cry 1 and cry 2 genes was observed in several CRC cell lines with reduced apoptosis and increased proliferation [18].

The up-regulation or down-regulation mediated effects of cry genes on cancer proliferation and apoptosis is usually explained by the connection of the circadian system to cell cycle control. The anti-proliferation factor wee1 is downregulated by the clock genes PER and CRY. The daily rhythm of wee 1 expression is abolished and exerts constitutively high levels in cry deficient mice [27]. Moreover, deficiency of cry $1 / 2$ protects the $p 53$ mutant mice against tumor development [7] and down-regulation of per2 induces the growth of mammary tumors in mice. On the other hand, the up-regulation of per2 increases levels of the pro-apoptotic protein bax and tumor suppressor protein $p 53$, while its down-regulation decreases levels of the anti-apoptotic proteins $b c l-2$ and $b c l-x$ in murine lung and breast carcinoma $[28,29]$. The tumor suppressive role of per2 is implicated also by the significant negative correlation between per2 expression in CRC and tumor staging [30]. Several genes involved in cell cycle control positively correlated (hus1, gadd45a, rb1, cdkn2a, $c d k 5 r p 1, m r e 11 a$, and sumo1) and some negatively correlated ( $c d c 20$ and birc5) with per2 expression in human CRC tissue cell cycle genes. Expression of these genes also depended on tumor staging [31].

In conclusion, we report pronounced changes in $c r y 1$ and cry 2 expression dependent on gender and tumor location. Expression of cry 1 was higher in tumors than in adjacent tissues in the right-sided colon but not in the left-sided colorectum in the entire patient cohort. This difference was preserved in women and the trend was observed in men. Higher expression of cryl in the right-sided colon tumor tissue was associated with worse survival only in women. While the expression of cry genes in tumor-adjacent tissue exerted a pronounced trend with increasing values toward the rectum, this trend was preserved only in the male cry 2 expression when tumor tissue was analyzed. We suggest that the differences in cry genes expression in tumor and adjacent tissue in specific groups of patients reflect the differences in carcinogenic processes in the right- and left-sided colorectum. Finally, our results emphasize the importance of distinguishing between the right-sided and left-sided origin of the primary tumor in gene expression screening studies.

Acknowledgements: This research was supported by grants APVV-14-0318, APVV-16-0209 and VEGA 1/0499/15.

\section{References}

[1] ALBRECHT U. Timing to perfection: the biology of central and peripheral circadian clocks. Neuron 2012; 74: 246-260. https://doi.org/10.1016/j.neuron.2012.04.006

[2] BUHR ED, TAKAHASHI JS. Molecular components of the Mammalian circadian clock. Handb Exp Pharmacol 2013; 217: 3-27. https://doi.org/10.1007/978-3-642-25950-0_1

[3] FU L, PELICANO H, LIU J, HUANG P, LEE C. The circadian gene period2 plays an important role in tumor suppression and DNA damage response in vivo. Cell 2002; 111: 41-50.

[4] SOTAK M, POLIDAROVA L, ERGANG P, SUMOVA A, PACHA J An association between clock genes and clockcontrolled cell cycle genes in murine colorectal tumors. Int J Cancer 2013; 132: 1032-1041. https://doi.org/10.1002/ ijc. 27760

[5] GAUGER MA, SANCAR A. Cryptochrome, circadian cycle, cell cycle checkpoints, and cancer. Cancer Res 2005; 65: 68286834. https://doi.org/10.1158/0008-5472.CAN-05-1119

[6] ANTOCH MP, GORBACHEVA VY, VYKHOVANETS O, TOSHKOV IA, KONDRATOV RV. Disruption of the circadian clock due to the Clock mutation has discrete effects on aging and carcinogenesis. Cell Cycle 2008; 7:1197-1204. https://doi.org/10.4161/cc.7.9.5886

[7] OZTURK N, LEE JH, GADDAMEEDHI S, SANCAR A. Loss of cryptochrome reduces cancer risk in p53 mutant mice. Proc Natl Acad Sci U S A 2009; 106: 2841-2846. https://doi. org/10.1073/pnas.0813028106 
[8] LEE JH, GADDAMEEDHIS, OZTURKN, YER, SANCARA. DNA damage-specific control of cell death by cryptochrome in p53-mutant ras-transformed cells. Cancer Res 2013; 73: 785-91. https://doi.org/10.1158/0008-5472.CAN-12-1994

[9] KANG TH, LINDSEY-BOLTZ LA, REARDON JT, SANCAR A. Circadian control of XPA and excision repair of cisplatinDNA damage by cryptochrome and HERC2 ubiquitin ligase. Proc Natl Acad Sci USA 2010; 107: 4890-4895. https://doi. org/10.1073/pnas.0915085107

[10] SANCAR A, LINDSEY-BOLTZ LA, GADDAMEEDHI S, SELBY CP, YE R, et al. Circadian clock, cancer, and chemotherapy. Biochemistry 2015; 54: 110-123. https:/doi. org/10.1021/bi5007354

[11] MERLANO MC, GRANETTO C, FEA E, RICCI V, GARRONE O. Heterogeneity of colon cancer: from bench to bedside. ESMO Open 2017; 2: e000218. https://doi.org/10.1136/ esmoopen-2017-000218

[12] PASKI SC, WIGHTMAN R, ROBERT ME, BERNSTEIN $\mathrm{CN}$. The importance of recognizing increased cecal inflammation in health and avoiding the misdiagnosis of nonspecific colitis. Am J Gastroenterol 2007; 102: 2294-2299. https://doi.org/10.1111/j.1572-0241.2007.01389.x

[13] MACFARLANE GT, MACFARLANE LE. Acquisition, evolution and maintenance of the normal gut microbiota. Dig Dis 2009; 27(Suppl. 1): 90-98. https://doi. org/10.1159/000268127

[14] LEE GH, MALIETZIS G, ASKARI A, BERNARDO D, ALHASSI HO et al. Is right-sided Colon cancer different to left-sided colorectal Cancer? - a systematic review. Eur J Surg Oncol 2015; 41: 300-308. https://doi.org/10.1016/j. ejso.2014.11.001

[15] KHASHAB MA, PICKHARDT PJ, KIM DH, REX DK. Colorectal anatomy in adults at computed tomography colonography: normal distribution and the effect of age, sex, and body mass index. Endoscopy 2009; 41: 674-678. https://doi. org/10.1055/s-0029-1214899

[16] VAYRYNEN JP, TUOMISTO A, VAYRYNEN SA, KLINTRUP K, KARHU T et al. Preoperative anemia in colorectal cancer: relationships with tumor characteristics, systemic inflammation, and survival. Sci Rep 2018; 8: 1126. https://doi. org/10.1038/s41598-018-19572-y.

[17] MAZZOCCOLI G, PANZA A, VALVANO MR, PALUMBO $\mathrm{O}$, CARELLA $\mathrm{M}$ et al. Clock gene expression levels and relationship with clinical and pathological features in colorectal cancer patients. Chronobiol Int 2011; 28: 841-851. https:// doi.org/10.3109/07420528.2011.615182

[18] MAZZOCCOLI G, COLANGELO T, PANZA A, RUBINO $\mathrm{R}, \mathrm{DE}$ CATA A et al. Deregulated expression of cryptochrome genes in human colorectal cancer. Mol Cancer 2016; 15: 6. https://doi.org/10.1186/s12943-016-0492-8

[19] YU H, MENG X, WU J, PAN C, YING X. Cryptochrome 1 overexpression correlates with tumor progression and poor prognosis in patients with colorectal cancer. PLoS One 2013; 8: e61679. https://doi.org/10.1371/journal.pone.0061679
[20] ELSALEH H, JOSEPH D, GRIEU F, ZEPS N, SPRY N et al. Association of tumor site and sex with survival benefit from adjuvant chemotherapy in colorectal cancer. Lancet 2000; 355: 1745-1750. https://doi.org/10.1016/S01406736(00)02261-3

[21] BOECKX N, JANSSENS K, VAN CAMP G, RASSCHAERT $\mathrm{M}$, PAPADIMITRIOU $\mathrm{K}$ et al. The predictive value of primary tumor location in patients with metastatic colorectal cancer: A systematic review. Crit Rev Oncol Hematol 2018; 121: 1-10. https://doi.org/10.1016/j.critrevonc.2017.11.003

[22] MAUS MK, HANNA DL, STEPHENS CL, ASTROW SH, YANG D et al. Distinct gene expression profiles of proximal and distal colorectal cancer: implications for cytotoxic and targeted therapy. Pharmacogenomics J 2015; 15: 354-362. https://doi.org/10.1038/tpj.2014.73

[23] HOOGERWERF WA, HELLMICH HL, CORNÉLISSEN G, HALBERG F, SHAHINIAN VB et al. Clock gene expression in the murine gastrointestinal tract: endogenous rhythmicity and effects of a feeding regimen. Gastroenterology 2007; 133: 1250-1260. https://doi.org/10.1053/j.gastro.2007.07.009

[24] MALLOY JN, PAULOSE JK, LI Y, CASSONE VM. Circadian rhythms of gastrointestinal function are regulated by both central and peripheral oscillators. Am J Physiol Gastrointest Liver Physiol 2012; 303: G461-473. https://doi.org/10.1152/ ajpgi.00369.2011

[25] POLIDAROVA L, SOTAK M, SLADEK M, PACHA J, SUMOVA A. Temporal gradient in the clock gene and cell-cycle checkpoint kinase Weel expression along the gut. Chronobiol Int 2009; 26: 607-620. https://doi. org/10.1080/07420520902924889

[26] HUISMAN SA, OKLEJEWICZ M, AHMADI AR, TAMANINI F, IJZERMANS JN et al. Colorectal liver metastases with a disrupted circadian rhythm phase shift the peripheral clock in liver and kidney. Int J Cancer 2015; 136: 1024-1032. https://doi.org/10.1002/ijc.29089

[27] MATSUO T, YAMAGUCHI S, MITSUI S, EMI A, SHIMODA F et al. Control mechanism of the circadian clock for timing of cell division in vivo. Science 2003; 302: 255-259. https://doi.org/10.1126/science.1086271

[28] YANG X, WOOD PA, ANSELL CH, HRUSHESKY WJM. Circadian time-dependent tumor suppressor function of period genes. Integr Cancer Ther 2009; 8: 309-316. https://doi. org/10.1177/1534735409352083

[29] HUA H, WANG Y, WAN C, LIU Y, ZHU B et al. Circadian gene mPer2 overexpression induces cancer cell apoptosis. Cancer Sci 2006; 97: 589-596. https://doi.org/10.1111/ j.1349-7006.2006.00225.x

[30] ZEMAN M, VICIAN M, MONOSIKOVA J, REIS R, HERICHOVA I. Deregulated expression of the per2 gene in human colorectal carcinoma. Mol Med Rep 2008; 1: 599-603.

[31] STORCELOVA M, VICIAN M, REIS R, ZEMAN M, HERICHOVA I. Expression of cell cycle regulatory factors hus1, gadd45a, rb1, cdkn2a and mre11a correlates with expression of clock gene per2 in human colorectal carcinoma tissue. Mol Biol Rep 2013; 40: 6351-6361. https://doi.org/10.1007/ s11033-013-2749-2 